\title{
Papers
}

\section{Randomised controlled trial of acute mental health care by a crisis resolution team: the north Islington crisis study}

Sonia Johnson, Fiona Nolan, Stephen Pilling, Andrew Sandor, John Hoult, Nigel McKenzie, Ian R White, Marie Thompson, Paul Bebbington

\begin{abstract}
Objective To evaluate the effectiveness of a crisis resolution team. Design Randomised controlled trial.

Participants 260 residents of the inner London Borough of Islington who were experiencing crises severe enough for hospital admission to be considered.

Interventions Acute care including a 24 hour crisis resolution team (experimental group), compared with standard care from inpatient services and community mental health teams (control group).

Main outcome measures Hospital admission and patients' satisfaction.

Results Patients in the experimental group were less likely to be admitted to hospital in the eight weeks after the crisis (odds ratio $0.19,95 \%$ confidence interval 0.11 to 0.32 ), though compulsory admission was not significantly reduced. A difference of 1.6 points in the mean score on the client satisfaction questionnaire (CSQ-8) was not quite significant $(\mathrm{P}=0.07)$, although it became so after adjustment for baseline characteristics $(\mathrm{P}=0.002)$. Conclusion Crisis resolution teams can reduce hospital admissions in mental health crises. They may also increase satisfaction in patients, but this was an equivocal finding.
\end{abstract}

\section{Introduction}

Crisis resolution teams are intended to reduce psychiatric bed use and provide rapid access to services. ${ }^{1-3}$ Their roles are to assess everyone for whom acute admission is considered and, whenever feasible, to provide intensive home treatment instead of admission. Unlike multidisciplinary community mental health teams, which provide continuing care for severely mentally ill patients in most areas of the United Kingdom, ${ }^{4}$ crisis resolution teams are available outside usual office hours. Crisis resolution teams can offer more frequent visits than community mental health teams: patients can usually be visited twice a day if required. Their input is short term: once the initial crisis has resolved, usually within a few weeks, they withdraw and community mental health teams provide longer term continuing care if needed. They are intended to be more acceptable to service users than hospital admission and to have a greater capacity to attend to the social factors that contribute to many crises. ${ }^{12}$

Government policy mandates introduction of crisis resolution teams throughout England, ${ }^{35}$ but supporting evidence has remained weak. ${ }^{6}$ Earlier studies of intensive home treatment initiated in emergencies provide only limited support ${ }^{7-9}$ as the experimental teams in these studies continued to provide care once the crisis had resolved. Moreover, control services did not include teams that routinely visited patients at home. No previous randomised trial has evaluated crisis resolution teams in the context of a modern community mental health system, although our recent naturalistic study suggested reduced admission rates and better patient satisfaction after their introduction. ${ }^{10}$

\section{Methods}

We tested whether involvement of a crisis resolution team in patients' care would result in lower admission rates within eight weeks of a crisis and in greater satisfaction with care.

\section{Setting}

The setting was two geographical sectors in the London Borough of Islington, where community mental health teams are well established. ${ }^{4}$ A multidisciplinary liaison team was available from 8 am to $10 \mathrm{pm}$ in the local casualty department, and two crisis houses, one for women only, provided alternatives to admission. Before the introduction of crisis resolution teams, Islington used fewer acute beds than other similarly deprived inner London boroughs. ${ }^{11}$

Sample

All residents aged 18 to 65 who were experiencing a crisis severe enough for mental health professionals to consider admission were eligible.

\section{Assignment}

Recruitment to a trial during a psychiatric crisis is a challenge: crises tend to occur unexpectedly, waiting for a researcher to arrive and conduct an interview before formulating a treatment plan is often unsafe and unfeasible, and patients often lack the capacity to make informed decisions. These problems probably account for the lack of recent randomised evaluations of crisis services and they required us to adapt usual trial recruitment procedures in several ways. As we wanted to minimise demands made on clinicians and patients at the time of the crisis, when patients initially presented we sought agreement only to the experimental intervention and not to the subsequent research interview. To achieve a reasonably representative sample, we also needed to design a procedure that allowed us to recruit people who lacked decisional capacity at the time of the crisis, often transiently.

Identification of study participants was thus the task not of researchers but of the community mental health teams, mental health liaison team, and on-call psychiatrists and approved social workers.. We obtained ethical approval to randomise:

- People who were willing and able to give informed consent to randomisation and care by the crisis resolution team

- People who lacked capacity to make a decision about their care at the time of the crisis but had received information about the trial before it began and had not decided to opt out. Before 
the trial began, 1160 people who had recently had contact with services were given the chance to opt out in advance if they did not want to be randomised; 100 did so

- People who lacked capacity at the time of the crisis and had not already been informed about the trial but whose carers assented to their entry.

Initial consent was to randomisation and receipt of the experimental intervention. We sought separate consent for the research interview at eight weeks. People randomised to the experimental intervention were subsequently given further written information by the crisis resolution team staff and offered another opportunity to refuse care from the team: for those initially lacking capacity, this was delayed until they had recovered it.

People identified by staff in the community mental health teams and other referring teams as meeting one of the above criteria for inclusion in the study were discussed with staff from the crisis resolution team. If crisis resolution team staff agreed that inclusion criteria were met, they telephoned the 24 hour randomisation service at the health services research unit, University of Aberdeen, which allocated participants at random to the experimental or control group. The research team was notified immediately about randomisations during office hours and on the next working day about randomisations that occurred out of hours.

People in crisis who did not meet the conditions for trial entry received standard care without the crisis resolution teams. In view of the complexity of these procedures, a member of the research team was on call 24 hours throughout the first three months of the trial to give advice.

\section{Interventions}

In the experimental group, a crisis resolution team augmented existing acute services and aimed to assess all patients and manage them at home if feasible. Staff were available 24 hours but on call from home after $10 \mathrm{pm}$. The control group received care from the inpatient unit, crisis houses, and community mental health teams.

\section{Data collection}

Baseline-As interviewing patients before randomisation was not feasible researchers collected baseline data from staff and clinical records as quickly as possible after randomisation. They recorded demographic details, clinical history, and presenting problems using structured questionnaires. They used the thresh- old assessment grid (TAG) ${ }^{12}$ and Health of the Nation outcome scales $(\mathrm{HoNOS})^{13}$ to elicit staff ratings of risks and severity of clinical and social problems at the time of the crisis.

Primary outcome measures-We used best available information from patients, staff, and clinical records to establish whether participants had been admitted to hospital in the eight weeks after the crisis. Patients' satisfaction was assessed at a research interview with the client satisfaction questionnaire, 8 item version (CSQ-8). ${ }^{14}$ Blinding researchers, clinicians, or patients was not feasible.

Secondary measures - At eight weeks, we collected data on days in hospital and crisis houses, and on compulsory detentions). At interview, symptoms were rated with the brief psychiatric rating scale $^{15}$ and quality of life with the Manchester short assessment of quality of life. ${ }^{16}$ Staff again made ratings on the Health of the Nation outcome scales and also rated social functioning with the life skills profile. ${ }^{17}$ At six months, patients were not interviewed, but we assessed service use, ratings on the Health of the Nation outcome scales and life skills profile, and adverse events, such as suicide attempts and violence, using information from staff and clinical records.

\section{Analysis}

We used data from our previous $s t u d y^{10}$ for the power calculation. We estimated that 134 participants per group would yield $90 \%$ power to detect a $20 \%$ difference in admission rates, while 85 per group would provide $90 \%$ power to detect a difference in satisfaction scores of half a standard deviation (3.8 points on the CSQ-8). Analysis was on an intention to treat basis. We calculated odds ratios and confidence intervals for categorical variables and mean differences and confidence intervals for quantitative data, except for bed use, for which we used Mann-Whitney tests because data were highly skewed, even after $\log$ transformation.

\section{Results}

\section{Randomisation}

We randomised 260 people, 135 to the experimental group and 125 to the control group. Of these, we interviewed 118 in the experimental group (87\%) and 108 in the control group (86\%) at eight weeks. The figure shows the randomisation process.

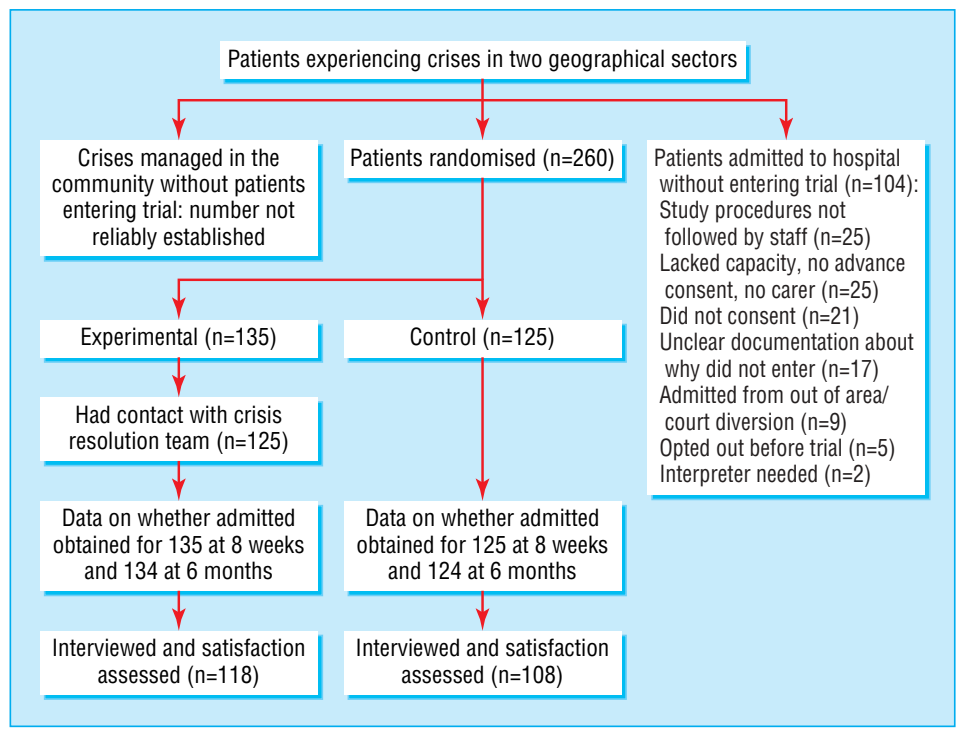

Flow of participants through study 
Table 1 Characteristics of experimental and control groups. Figures are numbers (percentages) of participants unless stated otherwise

\begin{tabular}{|c|c|c|}
\hline Characteristic & $\begin{array}{l}\text { Experimental } \\
\text { group }(n=135\end{array}$ & $\begin{array}{l}\text { Control group } \\
(\mathrm{n}=125)\end{array}$ \\
\hline Men & $65(48)$ & $67(54)$ \\
\hline Mean (SD) age (years) & $38.0(11.9)$ & $37.8(11.7)$ \\
\hline \multicolumn{3}{|l|}{ Ethnic group: } \\
\hline White British & $73(54)$ & $59(47)$ \\
\hline White Irish & $20(15)$ & $12(10)$ \\
\hline Other white & $9(7)$ & $19(15)$ \\
\hline Black Caribbean & $10(7)$ & $10(8)$ \\
\hline Black African & $8(6)$ & $11(9)$ \\
\hline Other black & $7(5)$ & $2(2)$ \\
\hline Asian & $3(2)$ & $3(2)$ \\
\hline Other or mixed & $5(4)$ & $9(7)$ \\
\hline Single, divorced, or widowed & $114(84)$ & $103(83)$ \\
\hline Living alone & $70(52)$ & $52(42)$ \\
\hline \multicolumn{3}{|l|}{ Accommodation: } \\
\hline Owner occupied & $9(7)$ & $18(14)$ \\
\hline Rented & $110(81)$ & $81(65)$ \\
\hline Supported & $10(7)$ & $17(14)$ \\
\hline Homeless (temporary accommodation) & $4(3)$ & $8(6)$ \\
\hline Homeless (roofless) & $2(1)$ & 1 (1) \\
\hline Employed in open market & $13(10)$ & $15(12)$ \\
\hline \multicolumn{3}{|l|}{ Clinical diagnosis: } \\
\hline Schizophrenia or schizoaffective disorder & $27(29)$ & $38(30)$ \\
\hline Bipolar affective disorder & $16(12)$ & $11(9)$ \\
\hline Other psychosis & $5(4)$ & $14(11)$ \\
\hline Unipolar depression & $41(31)$ & $38(30)$ \\
\hline Personality disorder & $23(17)$ & $12(10)$ \\
\hline Other non-psychotic disorder & $5(4)$ & $5(4)$ \\
\hline Substance misuse only & $6(5)$ & $7(6)$ \\
\hline $\begin{array}{l}\text { Substance misuse or dependence (sole diagnosis } \\
\text { or comorbid) }\end{array}$ & $65(48)$ & $47(38)$ \\
\hline Previous psychiatric admission & $93(69)$ & $89(71)$ \\
\hline \multicolumn{3}{|c|}{ Staff ratings of severity of risks (mean (SD) TAG scores): } \\
\hline Risk of intentional self harm & $1.3(1.1)$ & $1.4(1.2)$ \\
\hline Risk of unintentional self harm & $0.8(0.9)$ & $0.9(1.0)$ \\
\hline Risk from others & $0.7(0.8)$ & $0.6(0.8)$ \\
\hline Risk to others & $0.9(1.1)$ & $1.0(1.2)$ \\
\hline \multicolumn{3}{|c|}{ Severity of clinical and social problems (mean (SD) HoNOS score): } \\
\hline Total & $15.9(4.5)$ & $17.4(4.5)$ \\
\hline Total symptom severity & $4.9(2.1)$ & $6.0(2.2)$ \\
\hline Total social problem severity & $6.4(2.9)$ & $6.6(3.0)$ \\
\hline
\end{tabular}

$\mathrm{TAG}=$ threshold assessment grid; HoNOS=Health of the Nation outcome scales.

\section{Patients excluded before randomisation}

Of the people who were admitted during the recruitment period, 104 did not enter the trial (figure). We compared these people with people in the control group who were admitted: the main differences were that those who did not enter the trial were more likely to be black Caribbean $(21 \% v 5 \%)$, having their first contact with mental health services (24\% v 12\%), admitted via the police (23\% v 10\%), and admitted compulsorily (50\% v 32\%).

The other group of patients in crisis who may not have entered the trial were those managed in the community without referral to the trial. Unlike admissions, we had no reliable mechanism for identifying them all. It is unlikely, however, that large numbers of community crises associated with a significant risk of admission were missed. In the present study, around 40 people a month per 100000 local population either entered the study or were admitted to hospital, bypassing the study. Our naturalistic study identified all crises over a nine month period in south Islington, adjacent to the present study area: there were around 34 emergency presentations per 100000 per month. ${ }^{10}$ Moreover, one north Islington sector was served by the same cri- sis resolution team as the current trial sectors but was not involved in the trial. The crisis resolution team received around 38 referrals per 100000 population per month from this sector (including patients admitted immediately after assessment). All the Islington sectors had similar service structures and demographic characteristics, so that these recruitment rates suggest that few crises managed in the community were missed during the trial period.

We also compared characteristics of people included in our previous naturalistic study ${ }^{10}$ and in the current study to assess the representativeness of the current study sample. Demographic characteristics were similar, but participants in the current study were significantly less likely to have been compulsorily admitted in the past two years $(18 \% v 27 \%)$, to be rated by staff as uncooperative at initial assessment $(16 \% v 28 \%)$, to have a diagnosis of schizophrenia $(25 \%$ v $34 \%)$ or to present with psychotic symptoms $(55 \% v 65 \%)$ or elevated $\operatorname{mood}(14 \% v 22 \%)$, and more likely to present with depressive symptoms (59\% v 42\%). This supported our impression that people who did not enter the trial tended to be severely ill patients who went to hospital, rather than people successfully managed at home by the community mental health teams.

\section{Sample characteristics}

Table 1 shows the baseline characteristics of the experimental and control groups. Random allocation resulted in largely similar groups, though total scores on the Health of the Nation outcome scales were significantly higher in the control group, reflecting higher symptom subscores.

\section{Admissions}

Patients in the experimental group were less likely than those in the control group to be admitted during the eight weeks after the crisis (table 2). This effect persisted six months after baseline and when we included admissions to crisis houses. It was reflected in fewer bed days. Over the initial eight weeks, the number needed to treat to prevent one admission was 2.65. However, there was no significant difference in compulsory detentions.

\section{Satisfaction}

Patients in the experimental group were slightly more satisfied with their care $(\mathrm{P}=0.07$, table 3$)$. After we adjusted for baseline characteristics the difference became significant $(\mathrm{P}=0.002)$. However, baseline characteristics should be treated with caution as they were reported by staff after randomisation had occurred: thus adjusted results are not necessarily more valid than unadjusted.

\section{Secondary outcomes}

Patients in the experimental group had less severe symptoms at eight weeks, though after we adjusted for baseline characteristics the difference was no longer significant (table 3). The adjusted difference in the scores on the Health of the Nation outcome scales was significant at eight weeks (better in the experimental group) but not at six months. Other outcomes showed no clearly significant differences.

\section{Adverse events}

By six months, two people in the experimental group had died: one was shot by the police while he was holding hostages at knifepoint, another died after an overdose. Two people in the control group died of natural causes, and the coroner returned an open verdict on one who was found dead in his flat. There were no significant differences over six months in rates of attempted suicide and violence or of participants losing their jobs, becoming homeless, or being victims of violence. 
Table 2 Use of mental health services in eight weeks and six months after psychiatric crisis according to treatment. Figures are numbers (percentages) of participants unless stated otherwise

\begin{tabular}{|c|c|c|c|c|}
\hline & Experimental group $\left(\mathrm{n}=135^{\star}\right)$ & Control group ( $n=125)$ & Odds ratio $(95 \% \mathrm{CI})$ & $P$ value \\
\hline \multicolumn{5}{|c|}{ Admission in eight weeks after crisis } \\
\hline \multicolumn{5}{|l|}{ Admitted to: } \\
\hline Psychiatric ward & $29(22)$ & $74(59)$ & 0.19 (0.11 to 0.32$)$ & $<0.0005$ \\
\hline Crisis house & $25(19)$ & $16(13)$ & $1.5(0.8$ to 3.1$)$ & 0.21 \\
\hline Hospital/crisis house & $49(36)$ & $86(69)$ & 0.26 (0.15 to 0.43$)$ & $<0.0005$ \\
\hline \multicolumn{5}{|l|}{ Bed days in hospital: } \\
\hline Mean (SD) & $6.4(14.7)$ & $17.4(21.1)$ & & $<0.0005 \dagger$ \\
\hline Median (IQR) & $0(0)$ & $5(32)$ & & \\
\hline \multicolumn{5}{|c|}{ Bed days in hospital/crisis house: } \\
\hline Mean (SD) & $9.2(15.6)$ & $19.5(20.6)$ & & $<0.0005 \dagger$ \\
\hline Median (IQR) & $0(13.5)$ & $11.5(33.5)$ & & \\
\hline \multicolumn{5}{|c|}{ Admission in six months after crisis } \\
\hline \multicolumn{5}{|l|}{ Admitted to: } \\
\hline Psychiatric ward & $39(29)$ & $84(67)$ & $0.20(0.12$ to 0.34$)$ & $<0.0005$ \\
\hline Crisis house & $33(24)$ & $22(18)$ & 1.5 (0.8 to 2.8$)$ & 0.18 \\
\hline Hospital/crisis house & $63(47)$ & $94(75)$ & 0.29 (0.17 to 0.49$)$ & $<0.0005$ \\
\hline \multicolumn{5}{|l|}{ Bed days in hospital: } \\
\hline Mean (SD) & $16.1(36.5)$ & $35.0(47.9)$ & & $<0.0005 \dagger$ \\
\hline Median (IQR) & $0(9)$ & $11(55)$ & & \\
\hline \multicolumn{5}{|c|}{ Bed days in hospital/crisis house: } \\
\hline Mean (SD) & $21.3(37.9)$ & $38.6(47.0)$ & & $<0.0005 \dagger$ \\
\hline Median (IQR) & $0(27.5)$ & $23(61)$ & & \\
\hline \multicolumn{5}{|c|}{ Compulsory detention under Mental Health Act after crisis } \\
\hline In eight weeks after crisis & $16(12)$ & $24(19)$ & $0.57(0.28$ to 1.1$)$ & 0.10 \\
\hline In six months after crisis & $24(18)$ & $32(26)$ & $0.63(0.35$ to 1.2$)$ & 0.13 \\
\hline
\end{tabular}

*Data missing for one in each group for admission by six months and one in experimental and two in control for bed use at both time points.

†Mann-Whitney test.

\section{Discussion}

Availability of a crisis resolution team was associated with a reduction in the admission rate at eight weeks from $59 \%$ to $22 \%$, indicating that the team achieved its goal of providing an alternative to acute admission, at least in the group recruited to the trial, among whom severely ill patients at risk of compulsory admission were probably under-represented. The impact, however, was mainly on voluntary admissions.

We found some evidence of an effect on satisfaction, especially after we adjusted for baseline characteristics, though measurement problems regarding these are discussed above. This effect was less than we found in our previous study ${ }^{10}$ and less than might have been expected from older controlled studies ${ }^{7}$ of home treatment and from uncontrolled surveys indicating positive views about crisis teams. ${ }^{18}{ }^{19}$ Views of both forms of treatment were on average mildly positive. One possibility is that use of a brief global measure failed to capture variations in views. Some patients may also have had reservations about crisis resolution teams, which have been criticised for lack of continuity of care. ${ }^{6}$

Clinical and social outcomes were otherwise similar, except for some evidence of differences in scores on the Health of the Nation outcome scales at eight weeks, which had disappeared by six months. This lack of substantial persisting differences is not surprising as the intervention period was brief, against a background of longstanding mental illness and social exclusion among many patients.

\section{Strengths and weaknesses}

The main strength of our study is that we succeeded in carrying out a randomised trial with an adequate sample size in an emer-

Table 3 Patients' satisfaction and clinical and social outcomes. Figures are mean (SD) score unless stated otherwise

\begin{tabular}{|c|c|c|c|c|c|c|}
\hline & \multirow[b]{2}{*}{$\begin{array}{c}\text { Experimental } \\
\text { group }\end{array}$} & \multirow[b]{2}{*}{$\begin{array}{c}\text { Control } \\
\text { group }\end{array}$} & \multicolumn{2}{|c|}{ Unadjusted } & \multicolumn{2}{|c|}{ Adjusted* $^{*}$} \\
\hline & & & $\begin{array}{l}\text { Mean difference } \\
(95 \% \mathrm{CI})\end{array}$ & $P$ value & $\begin{array}{l}\text { Mean difference } \\
(95 \% \mathrm{CI})\end{array}$ & $P$ value \\
\hline \multicolumn{7}{|c|}{ Outcomes measured at interview 8 weeks after crisis (118 interviewed in intervention; 108 in control) $\dagger$} \\
\hline Patient satisfaction: CSQ-8 & $22.8(6.6)$ & $21.2(7.3)$ & $1.7(-0.1$ to 3.5$)$ & 0.074 & $3.0(1.1$ to 4.9$)$ & 0.002 \\
\hline Symptom severity: total BPRS & $36.1(9.0)$ & $39.0(10.8)$ & $-2.9(-5.6$ to -0.1$)$ & 0.041 & $-2.2(-5.1$ to 0.7$)$ & 0.14 \\
\hline Quality of life: total MANSA & $45.6(13.2)$ & $47.1(14.7)$ & $-1.5(-5.2$ to 2.2$)$ & 0.43 & $-1.0(-4.8$ to 2.8$)$ & 0.61 \\
\hline \multicolumn{7}{|c|}{ Outcomes rated by staff eight weeks after crisis (133 in intervention; 124 in control) } \\
\hline Severity of clinical and social problems: total HoNOS & $9.9(4.5)$ & $11.8(6.0)$ & $-1.9(-3.3$ to -0.6$)$ & 0.004 & $-2.2(-3.5$ to -1.0$)$ & 0.001 \\
\hline Social functioning: total LSP & $132.0(13.2)$ & $129.0(17.0)$ & $3.0(-0.8$ to 6.9$)$ & 0.12 & $3.3(-0.1$ to 6.8$)$ & 0.059 \\
\hline \multicolumn{7}{|c|}{ Outcomes rated by staff six months after crisis (133 in intervention; 122 in control) } \\
\hline Severity of clinical and social problems: total HoNOS & $9.8(5.5)$ & $10.4(6.4)$ & $-0.6(-2.2$ to 0.9$)$ & 0.43 & $-1.0(-2.5$ to 0.5$)$ & 0.21 \\
\hline Social functioning: total LSP & $133.2(14.7)$ & $132.2(16.1)$ & $1.1(-3.0$ to 5.1$)$ & 0.61 & $1.2(-2.5$ to 4.8$)$ & 0.53 \\
\hline
\end{tabular}

CSQ-8=client satisfaction questionnaire-8 item version; BPRS=brief psychiatric rating scale; MANSA=Manchester short assessment of quality of life; HoNOS=Health of the Nation outcome scales; LSP=life skills profile (higher score indicates poorer functioning).

${ }^{*}$ Adjusted for all baseline variables listed in table 1 . To avoid large numbers of independent variables, some categories were combined (for example, all forms of permanent and unsupported housing).

tOf interviewed sample, satisfaction rated for all; missing values for BPRS for 11 experimental and 4 control participants, and for MANSA for 4 experimental and 5 control participants. 


\section{What is already known on this topic}

Crisis resolution teams are currently being introduced throughout England as part of national mental health policy

No randomised evaluation of this service model has been carried out in a modern community mental health system

\section{What this study adds}

Crisis resolution teams can prevent some psychiatric hospital admissions, especially voluntary ones

In this group of patients with acute mental health emergencies, people who received care from a crisis resolution team tended to be more satisfied with their care

gency situation, despite the considerable practical difficulties this poses. Response rates for those included were good.

Lack of assessment before baseline is a limitation. We relied on randomisation to produce comparable groups. The similarity of the groups on most characteristics suggests this succeeded. However, we do not know whether the baseline differences we did find-for example, in scores on the Health of the Nation outcome scales)-occurred by chance or were early treatment effects.

More important, however, was the exclusion of a substantial group of admitted patients who were probably more disturbed on average than the group entering the trial and of some patients managed in the community without referral to the trial. Such exclusions are inevitable in randomised controlled trials, though often unreported. ${ }^{20}$ This is the reason why we conducted a complementary before and after quasi-experimental study in the adjacent part of Islington, ${ }^{10}$ in which we controlled for baseline variables and did not exclude any eligible patients. The fact that both studies showed that crisis resolution teams were associated with reduced admissions after crises supports our conclusions. While the exclusion of a more severely unwell group may exaggerate the effect size in the current study, the routinely collected admissions data for the study area before and after the trial are interesting. In the 12 months before the introduction of the crisis resolution team, there were 340 admissions. In the 12 months after the trial, when randomisation had ended and the crisis resolution team was involved in all decisions to admit, there were 237.

Finally, generalisability is limited by the distinctive characteristics of psychiatric patients in inner London, among whom psychosis, social isolation, substance misuse and compulsory treatment are common..$^{21}$ These characteristics, however, may make Islington a particularly stringent test of the effectiveness of crisis resolution teams, as achieving a reduction in bed use in this setting is especially challenging.

We are grateful to all the patients and clinicians who participated in the study and to Tom Craig (chair), Jonathan Bindman, and Paul McCrone for participating in the trial steering committee.

Contributors: SJ, FN, SP, JH, NM, AS, MT, and PB developed the study protocol and helped implement it. FN coordinated data collection, and MT and AS also collected data. IRW provided statistical advice throughout the study. SJ analysed the data and is guarantor for the study. SJ, FN, SP, JH, NM, AS, IRW, and $\mathrm{PB}$ wrote the paper.
Funding: Camden and Islington Health Authority and the Department of Health. The contributors are independent of these bodies, except that several of us have contracts with a Mental Health Trust whose services were commissioned by Camden and Islington Health Authority.

Competing interests: None declared.

Ethical approval: Camden and Islington community research ethics committee (reference 00/23).

1 Smyth MG, Hoult J. The home treatment enigma. BMJ 2000;320:305-8.

2 Johnson S. Crisis resolution and home treatment teams. Psychiatry 2004;3:22-5.

3 Department of Health. Crisis resolution/home treatment teams. Mental Health Policy Implementation Guide. London: Department of Health, 2001.

4 Johnson S, Zinkler M, Priebe S. Mental health service provision in England. Acta Psychiatrica Scand Suppl 2001;410:47-55.

Department of Health. The NHS plan. London: Stationery Office, 2000.

6 Pelosi AJ, Jackson GA. Home treatment-enigmas and fantasies. BMJ 2000;320:308-9.

7 Hoult J, Reynolds I, Charbonneau-Powis M, Weekes P, Briggs J. Psychiatric hospital versus community treatment: the results of a randomised trial. Austr N Z J Psychiatry sus community

8 Stein LI, Test MA. Alternative to mental hospital treatment. I. Conceptual model, treatment program, and clinical evaluation. Arch Gen Psychiatry 1980;37:392-7.

9 Marks I, Connolly J, Muijen M, Audini B, McNamee G, Lawrence R. Home-based versus hospital-based care for people with serious mental illness. Br J Psychiatry 1994; 65:179-94.

10 Johnson S, Nolan F, Hoult J, White IR, Bebbington P, Sandor A, et al. Outcomes of crises before and after introduction of a crisis resolution team. $\mathrm{Br} J$ Psychiatry 2005; $187: 68-75$

11 Ramsay R, Thornicroft G, Johnson S, Brooks L, Glover G. Levels of in-patient and residential provision throughout London. In: Johnson S, Ramsay R, Thornicroft G, Brooks L, Lelliot P, Peck E, et al, eds. London's mental health. London: Kings Fund Publishing, 1997

12 Slade M, Powell R, Rosen A, Strathdee G. Threshold assessment grid (TAG): the development of a valid and brief scale to assess the severity of mental illness. Soc Psychiatry Psychiatr Epidemiol 2000;35:78-85.

13 Wing JK, Beevor AS, Curtis RH, Park SB, Hadden S, Burns A. Health of the Nation Outcome Scales (HoNOS). Research and development. Br J Psychiatry 1998;172:11-8.

14 Attkisson CC, Zwick R. The client satisfaction questionnaire: psychometric properties and correlations with service utilization and psychotherapy outcome. Eval Prog Plan 1982;5:233-7.

15 Lukoff D, Liberman RP, Neuchterlein KH. Symptom monitoring in the rehabilitation of schizophrenic patients. Schizophr Bull 1986;12:578-93.

16 Priebe S, Huxley P, Knight S, Evans S. Application and results of the Manchester short assessment of quality of life (MANSA). Int J Soc Psychiatry 1999;45:7-12.

17 Parker G, Rosen A, Emdur N, Hadzi-Pavlov D. The life skills profile: psychometric properties of a measure assessing function and disability in schizophrenia. Acta Psychiatrica Scand 1991;83:145-52.

18 Cohen B. Providing intensive home treatment: inter-agency and inter-professional issues. In: Brimblecombe $\mathrm{N}$, ed. Acute mental health care in the community: intensive home treatment. London: Whurr, 2001

19 Reynolds I, Jones JE, Berry DW, Hoult JE. A crisis team for the mentally ill: the effect on patients, relatives and admissions. Med J Aust 1990;152:646-52.

20 Britton A, McKee M, Black N, McPherson K, Sanderson C, Bain C. Threats to applicability of randomised trials: exclusions and selective participation.J Health Serv Res Policy $1999 ; 4: 112-21$.

21 Johnson S, Ramsay R, Thornicroft G, Brooks L, Lelliott P, Peck E, et al, eds. London's mental health. London: Kings Fund Publishing, 1997.

(Accepted 8 June 2005)

doi 10.1136/bmj.38519.678148.8F

Department of Mental Health Sciences, Royal Free and University College Medical Schools, University College London, London W1W 7EY

Sonia Johnson senior lecturer in social and community psychiatry

Paul Bebbington professor of social and community psychiatry

Camden and Islington Mental Health and Social Care Trust, London NW1 0PE

Fiona Nolan research fellow in mental health nursing

John Hoult consultant psychiatrist

Nigel McKenzie consultant psychiatrist

CORE (British Psychological Psychology), Sub-Department of Clinical Health

Psychology, University College London, London WC1E 7HB

Stephen Pilling Director

Central and North West London Mental Health NHS Trust, London W2 6LA

Andrew Sandor consultant psychiatrist

MRC Biostatistics Unit, Cambridge CB2 2SR

Ian R White senior scientist

Department of Clinical Psychology, University of Surrey, Guildford, Surrey GU2 7XH

Marie Thompson trainee clinical psychologist

Correspondence to: S Johnson s.johnson@ucl.ac.uk 